\title{
Abnormalities of Lipoprotein and Carbohydrate Metabolism in Degenerative Diseases of the Nervous System - Motor Neuron Disease and Spinocerebellar Degeneration
}

\author{
Atsushi Murai, ${ }^{*}$ Tadao Miyahara, Tomoji Tanaka, \\ Takeshi Kaneko, Yoshiyasu Sako and Masakuni \\ KAMEYAMA \\ Department of Geriatrics, Kyoto University Hospital, Sakyoku, \\ Kyoto 606
}

Murai, A., Miyahara, T., Tanaka, T., Kaneko, T., Sako, Y. and Kameyama, M. Abnormalities of Lipoprotein and Carbohydrate Metabolism in Degenerative Diseases of the Nervous System-Motor Neuron Disease and Spinocerebellar Degeneration. Tohoku J. exp. Med., 1983, 139 (4), 365-376 _ The levels of plasma high density lipoprotein (HDL) cholesterol and plasma triglyceride were determined in 44 patients with motor neuron disease (MND) and in 36 patients with spinocerebellar degeneration (SCD). In both groups the HDL cholesterol levels were significantly lower than those in healthy controls, whereas the plasma triglyceride levels were higher than those in the controls. Glucose levels during the oral glucose tolerance test (GTT) were significantly higher in both MND and SCD groups than in healthy controls. Immunoreactive insulin (IRI) levels during GTT were rather higher at 0 and $120 \mathrm{~min}$ in both MND and SCD groups than in healthy controls. Glycosylated hemoglobin levels were lower in MND than in the controls. These results indicate that both lipoprotein and carbohydrate metabolisms were impaired in MND and SCD groups. The possibility was presented that denervation might play a part in the pathogenesis of abnormalities of lipoprotein and carbohydrate metabolisms. - motor neuron disease; spinocerebellar degeneration; high density lipoprotein; glucose tolerance test; glycosylated hemoglobin

A number of studies have shown a high incidence of impaired glucose metabolism in patients with amyotrophic lateral sclerosis (ALS) (Ionăşescu and Luca 1964; Steinke and Tyler 1964; Quick and Greer 1967; Collis and Engel 1968; Ionăşescu et al. 1968; Mueller and Quick 1970; Utterback et al. 1970; Gotoh et al. 1972; Gustafson and Störtebecker 1972; Koerner 1976; Nagano et al. 1979). Abnormalities of glucose metabolism are not only specific to patients with ALs but

Received for publication, June 14, 1982.

* To whom reprint requests should be sent.

Abbreviations used are: HDL, high density lipoprotein; VLDL, very low density lipoprotein; LPL, lipoprotein lipase; GTT, glucose tolerance test; IRI, immunoreactive insulin; MND, motor neuron disease; ALS, amyotrophic lateral sclerosis; SPMA, spinal progressive muscular atrophy; SCD, spinocerebellar degeneration; OPCA, olivopontocerebellar atrophy; LCCA, late cerebellar cortical atrophy; SDS, Shy-Drager syndrome. 
also are frequently associated with a wide variety of neurologic and neuromuscular disorders most of which involve muscle wasting: Parkinson's disease (Boyd et al. 1971; Van Woert and Mueller 1971; Lipman et al. 1974; National Diabetes Data Group 1979), Huntington's chorea (Podolsky et al. 1972), muscular dystrophy (Dreyfus et al. 1954; Danowski et al. 1956; Ionăşescu and Luca 1963), myotonic dystrophy (Nadler et al. 1950; Jacobson et al. 1955; Marshall 1959; Caughey and Saucier 1962; Lee and Hughes 1964), chronic peripheral neuropathy (Collis and Engel 1968), late onset proximal myopathy (Collis and Engel 1968), cerebrovascular disease (Jakobson 1967; Gertler et al. 1972), Friedreich's ataxia (Podolsky et al. 1964; Hewér and Robinson 1968; Podolsky and Sheremata 1970; Podolsky 1975), and ataxia telangiectasia (Barlow et al. 1965). However, very little is known about glucose metabolism in other forms of spinocerebellar degeneration (SCD). Moreover, the insulin response to glucose loading has been investigated extensively but has not provided any consistent results (Mueller and Quick 1970; Van Woert and Mueller 1971; Gotoh et al. 1972; Gustafson and Störtebecker 1972; Podolsky et al. 1972; Nagano et al. 1979).

Only a few reports have been published on lipid and lipoprotein metabolism in ALS. Mueller et al. (1970) showed significantly elevated fasting concentrations of serum free fatty acid and cholesterol in ALS. Gustafson and Störtebecker (1972) found that the incidence of type II hyperlipoproteinemia was higher in ALS, particularly in cases of short duration than in controls, and type IV hyperlipoproteinemia was found in ALS patients with more advanced cervical and lumbar motor neuron lesions. In these two studies, high density lipoprotein (HDL) was not separated to estimate HDL cholesterol level. Huang et al. (1978) recently reported the reduced level and abnormal composition of HDL in Friedreich's ataxia and familial spastic ataxia but subsequently Walker et al. (1980) could not confirm this finding.

In the present study attempts were made to disclose the profile of lipoprotein and carbohydrate metabolism characteristic of two degenerative diseases of the nervous system; motor neuron disease (MND) and SCD. The abnormal metabolisms common to these two distinct diseases were found and a possible mechanism for metabolic abnormalities was discussed.

\section{Subjects ANd Methods}

The subjects studied were 44 consecutive patients with MND and 36 consecutive patients with SCD in whom plasma lipid and HDL cholesterol levels were determined. The MND group consisted of 32 male and 12 female patients; the former subgroup contained 23 ALS patients and 9 patients with spinal progressive muscular atrophy (SPMA), and the latter group contained 11 ALS patients and one SPMA patient. The SCD group consisted of 21 male and 15 female patients; the former subgroup was composed of 12 patients with olivopontocerebellar atrophy (OPCA), 2 patients with late cerebellar cortical atrophy (LCCA), 4 patients with Shy-Drager syndrome (SDS) and 3 patients with other forms of SCD, and the latter subgroup was composed of 11 patients with OPCA, 3 patients with LCCA and one patient with SDS. Patients with paraneoplastic cerebellar degeneration were excluded from this study. The diagnosis was established by the patient's history, neurologic 
examination, clinical course, electromyography, computerized axial tomography of the brain and cervical vertebrae.

Two healthy control groups consisting of medical staff members were set up; one was a group for comparison of lipoprotein metabolism (53 males and 20 females) and the other was a group for comparison of carbohydrate metabolism (16 males and one female) from which obese subjects (relative weight over $115 \%$ ) or subjects with a family history of diabetes mellitus had been excluded. The relative weight was estimated by the table of Metropolitan Life Insurance Company (1942, 1943).

For the determination of plasma lipoprotein concentration, venous blood was drawn after an overnight fast. HDL cholesterol level was measured by the heparin-Ca precipitation method of Noma et al. (1978). The concentrations of plasma and HDL cholesterol and plasma triglyceride were determined by enzymatic methods. In 32 MND patients and 20 SCD patients, $50 \mathrm{~g}$ oral GTT was performed and glucose levels of whole venous blood were determined by an Auto Analyzer using the ferricyanide method. The patients were classified into diabetes mellitus, impaired glucose tolerance and normal groups according to the new criteria proposed by the National Diabetes Data Group (1979). The plasma concentrations of immunoreactive insulin (IRI) were measured by a double antibody radioimmunoassay method. The level of glycosylated hemoglobin was determined using Quik-Sep (Isolab Inc.).

\section{Results}

\section{Lipid and lipoprotein metabolism}

Plasma cholesterol. The mean values of plasma cholesterol levels were 187.8, $189.8,181.5$ and $185.4 \mathrm{mg} / 100 \mathrm{ml}$ in male and female MND groups and male and female SCD groups, respectively (Tables 1,2). These values were not significantly different from the mean values of the healthy control group. According to the duration of disease, the newer patient was compared with his counterpart who had a longer duration of disease as follows: (i) Patients with MND were subdivided into a "new" group in which the duration was one year or less and an "old" group in which the duration was more than one year. (ii) Patients with SCD were subdivided into a "new" group in which the duration was three years or less and an

TABLE 1. Lipid and lipoprotein profiles of male healthy controls and of male patients with $M N D$ and $S C D$

\begin{tabular}{|c|c|c|c|c|c|c|}
\hline & \multirow{2}{*}{$\begin{array}{c}\text { Number of } \\
\text { cases }\end{array}$} & \multirow{2}{*}{$\begin{array}{c}\text { Age } \\
\text { (years) }\end{array}$} & \multirow{2}{*}{$\begin{array}{c}\text { Relative } \\
\text { weight (\%) }\end{array}$} & \multicolumn{2}{|c|}{ Cholesterol $(\mathrm{mg} / 100 \mathrm{ml})$} & \multirow{2}{*}{$\begin{array}{l}\text { Triglyceride } \\
(\mathrm{mg} / 100 \mathrm{ml})\end{array}$} \\
\hline & & & & Plasma & HDL & \\
\hline $\begin{array}{l}\text { Healthy } \\
\text { control }\end{array}$ & 53 & $34.2 \pm 10.2$ & $98.5 \pm 9.8$ & 181. $6 \pm 34.1$ & 52. $1 \pm 12.1$ & $95.2 \pm 36.9$ \\
\hline MND & 32 & $47.0 \pm 11.3$ & $95.3 \pm 8.8$ & $187.8 \pm 30$ & $41.8 \pm 9.8_{+}^{+}$ & $160.2 \pm 98.1 \ddagger$ \\
\hline ALS & 23 & $46.2 \pm 12.3$ & $94.9 \pm 9.5$ & 180. & $41.3 \pm 8.1_{+}^{+}$ & $153.3 \pm 101.2_{+}^{+}$ \\
\hline SPMA & 9 & $49.2 \pm 8.4$ & $96.2 \pm 7.4$ & 206.3 & $42.9 \pm 13.8 \dagger$ & $177.8 \pm 93.0 \dagger$ \\
\hline SCD & 21 & $55.3 \pm$ & 97.2 & 181 & $3 \pm 6.3 \ddagger$ & $139.2 \pm 50.7 \ddagger$ \\
\hline OPCA & 12 & $57.3 \pm 10.8$ & $98.3 \pm 20.0$ & & $38.4 \pm 5.3_{\ddagger}^{+}$ & $124.7 \pm 38.9^{+}$ \\
\hline LCCA & 2 & $59.0 \pm 17.0$ & $102.5 \pm 20.5$ & $182.0 \pm 25$ & $48.5 \pm 12.0$ & $154.5 \pm 38.9$ \\
\hline SDS & 4 & $59.3 \pm 9.7$ & $92.0 \pm 20.0$ & $192.5 \pm 37.0$ & $35.8 \pm 5.0_{+}^{\dagger}$ & $119.8 \pm 12.1^{*}$ \\
\hline Others & 3 & $39.7 \pm 11.5$ & $95.5 \pm 2.1$ & $212.7 \pm 10.7$ & $41.7 \pm 2.5$ & $213.0 \pm 77.7$ \\
\hline
\end{tabular}

Values are exprssed as mean \pm s.D.

Significant differences (Student's $t$-test) are indicated as: ${ }^{*} p<0.05 ; \dagger p<0.01 ; \ddagger p<0.005$. 
TABLE 2. Lipid and lipoprotein profiles of female healthy controls and of female patients with $M N D$ and $S C D$

\begin{tabular}{ccccccc} 
& $\begin{array}{c}\text { Number of } \\
\text { cases }\end{array}$ & $\begin{array}{c}\text { Age } \\
\text { (years) }\end{array}$ & $\begin{array}{c}\text { Relative } \\
\text { weight }(\%)\end{array}$ & \multicolumn{2}{c}{ Cholesterol $(\mathrm{mg} / 100 \mathrm{ml})$} & $\begin{array}{c}\text { Triglyceride } \\
(\mathrm{mg} / \mathbf{1 0 0} \mathrm{ml})\end{array}$ \\
\hline $\begin{array}{c}\text { Healthy } \\
\text { control }\end{array}$ & 20 & $32.9 \pm 10.4$ & $93.0 \pm 9.2$ & $179.2 \pm 36.0$ & $59.8 \pm 8.7$ & $83.9 \pm 31.1$ \\
& & & & & & \\
MND & 12 & $57.9 \pm 11.6$ & $88.9 \pm 12.6$ & $189.8 \pm 28.2$ & $49.5 \pm 9.0 \dagger$ & $100.0 \pm 38.5$ \\
ALS & 11 & $59.2 \pm 11.2$ & $91.6 \pm 10.2$ & $191.2 \pm 29.2$ & $48.5 \pm 8.8+$ & $104.5 \pm 37.0^{*}$ \\
SPMA & 1 & 44 & 67.0 & 175 & 60 & 51 \\
SCD & 15 & $57.1 \pm 12.2$ & $98.1 \pm 13.1$ & $185.4 \pm 35.9$ & $47.9 \pm 10.9 \ddagger$ & $126.1 \pm 63.4^{*}$ \\
OPCA & 11 & $57.2 \pm 12.6$ & $100.0 \pm 14.0$ & $174.8 \pm 31.8$ & $45.5 \pm 8.7 \ddagger$ & $123.5 \pm 60.2^{*}$ \\
LCCA & 3 & $56.7 \pm 15.7$ & $96.0 \pm 1.4$ & $229.7 \pm 15.7$ & $59.7 \pm 13.3$ & $147.3 \pm 93.2^{*}$ \\
SDS & 1 & 58 & 83.0 & 169 & 40 & 91 \\
\hline
\end{tabular}

Values are expressed as mean \pm s.D.

Significant differences (Student's $t$-test) are indicated as: $* p<0.05 ; \uparrow p<0.01 ; \ddagger p<0.005$.

"old" group in which the duration was over three years. No significant differences in plasma cholesterol levels were found between the new and old subgroups (Table 3). These results were not compatible with the findings reported by Gustafson and Störtebecker (1972) in which the new ALS patients frequently had hypercholesterolemia.

$H D L$ cholesterol. The mean values of HDL cholesterol level were 41.8, 49.5, 39.3 and $47.9 \mathrm{mg} / 100 \mathrm{ml}$ in male and female MND groups and male and female SCD groups, respectively. Each of these values was significantly lower than the mean value of the healthy control group (Tables 1,2). According to the degree of disability, each group was divided into two subgroups: a mobile group in which patients were able to walk unaided and an immobile group in which the patients

TABLE 3. Comparison of lipid and lipoprotein profile of the new patients

\begin{tabular}{|c|c|c|c|c|c|}
\hline & \multirow{3}{*}{$\begin{array}{c}\text { Number of } \\
\text { cases }\end{array}$} & \multicolumn{3}{|c|}{ Male } & \multirow{3}{*}{$\begin{array}{l}\text { Triglyceride } \\
(\mathrm{mg} / 100 \mathrm{ml})\end{array}$} \\
\hline & & \multirow{2}{*}{$\begin{array}{c}\text { Age } \\
\text { (years) }\end{array}$} & \multicolumn{2}{|c|}{ Cholesterol $(\mathrm{mg} / 100 \mathrm{ml})$} & \\
\hline & & & Plasma & HDL & \\
\hline \multicolumn{6}{|l|}{ MND } \\
\hline $\begin{array}{l}\text { New } \\
\quad(\leq 1 \text { year })\end{array}$ & 10 & $46.9 \pm 9.6$ & $\begin{array}{c}\text { 179. } 2 \pm 34.0 \\
\text { N.S. }\end{array}$ & $36.5 \pm 7.7 *$ & $\begin{array}{c}\text { 211. } 6 \pm 140.9 \\
\text { N.S. }\end{array}$ \\
\hline$\stackrel{\text { Old }}{(>1 \text { year })}$ & 21 & $47.6 \pm 12.3$ & $193.1 \pm 28.9$ & $44.3 \pm 10.1$ & $138.9 \pm 63.0$ \\
\hline \multicolumn{6}{|l|}{ SCD } \\
\hline $\begin{array}{l}\text { New } \\
(\leq 3 \text { years })\end{array}$ & 10 & 55. $2 \pm 13.9$ & $176.5 \pm 30.6$ & $\begin{array}{c}36.7 \pm 4.6 \\
\text { N.S. }\end{array}$ & $133.1 \pm 60.6$ \\
\hline $\begin{array}{l}\text { old } \\
(>3 \text { years })\end{array}$ & 8 & $56.6 \pm 12.9$ & $179.4 \pm 33.1$ & $42.6 \pm 7.4$ & $155.1 \pm 45.4$ \\
\hline
\end{tabular}

Values are expressed as mean \pm s.D.

Significant differences (Student's $t$-test) are indicated as: N.S., not significant; of disease. 
were unable to walk without aid. There were no significant differences between these two subgroups, suggesting that the HDL cholesterol level was independent of the extent of the patient's disability (not shown). When the new patient group was compared with the old counterpart as described above, the HDL cholesterol level was lower in the new MND group than in the old counterpart (Table 3). This difference was considered to be due to the fact that in the old MND group slowly progressive patients rather than more advanced patients predominated.

Triglyceride. In males, the triglyceride levels of MND and SCD groups and their subgroups were significantly higher than that of the healthy control group (Tables 1, 2). Similarly, the triglyceride level was significantly higher in the female SCD group than in the female control group, whereas this difference between the female MND group and female control group was not significant. When the plasma triglyceride level in the old patient group was compared with that of the new patient group, there were no significant differences between them (Table 3). Similarly, there were no significant differences in plasma triglyceride levels between the mobile and immobile groups in both MND and SCD groups (not shown). These findings were not compatible with those reported by Gustafson et al (1972). Triglyceride levels were inversely correlated with HDL cholesterol levels in MND ( $r=-0.435$ for males, $r=-0.06$ for females), whereas there was no correlation between them in SCD.

\section{Carbohydrate metabolism}

Glucose level of whole venous blood during $50 \mathrm{~g}$ oral GTT. The mean values of 0 (fasting), 30,60 and 120 min glucose levels were higher in both MND and SCD groups than in the healthy control group, respectively (Table 4). The differences in glucose levels between MND and SCD groups and the healthy con-

\begin{tabular}{|c|c|c|c|c|}
\hline \multirow{3}{*}{$\begin{array}{c}\text { Number of } \\
\text { cases }\end{array}$} & \multicolumn{3}{|c|}{ Female } & \multirow{3}{*}{$\begin{array}{l}\text { Triglyceride } \\
(\mathrm{mg} / 100 \mathrm{ml})\end{array}$} \\
\hline & \multirow{2}{*}{$\begin{array}{c}\text { Age } \\
\text { (years) }\end{array}$} & \multicolumn{2}{|c|}{ Cholesterol (mg/100 m) } & \\
\hline & & Plasma & HDL & \\
\hline 6 & $62.2 \pm 11.4$ & $185.8 \pm 9.7$ & $47.7 \pm 8.6$ & $112.0 \pm 50.4$ \\
\hline 4 & $48.0 \pm 7.5$ & $169.8 \pm 16.5$ & $45.3 \pm 3.5$ & $81.8 \pm 20.8$ \\
\hline 6 & $59.3 \pm 11.6$ & $185.5 \pm 28.3$ & $45.5 \pm 8.1$ & $149.7 \pm 67.4$ \\
\hline 7 & $53.7 \pm 14.4$ & $181.1 \pm 46.8$ & $46.3 \pm 9.5$ & $115.7 \pm 66.9$ \\
\hline
\end{tabular}


trol group reached statistical significance at 30,60 and $120 \mathrm{~min}$. When only ALS or OPCA patients were tested and their glucose levels were compared with those of the control group, similar results were obtained except for the glucose levels at 0 and $30 \mathrm{~min}$ in the ALS group (Table 4). If the patients were classified according to the new criteria proposed by the National Diabetes Data Group (1979), the incidence of diabetes mellitus plus impaired glucose tolerance was $51.6 \%$ in the MND group and $40 \%$ in the SCD group (Table 5). These incidences are undoubtedly higher than those of the general population, indicating that glucose metabolisms are impaired in SCD as well as in MND as previously reported. The MND group had no obese patients having a relative weight of over $115 \%$ but in the SCD group 3 patients were obese; 2 male and one female OPCA patients had relative weights of 117,147 and $118 \%$, respectively. Hence, the impaired glucose metabolism observed in MND or SCD patients is considered independent of obesity.

TABLE 4. Glucose levels of venous whole blood during $50 \mathrm{~g}$ oral GTT

\begin{tabular}{cccccccc}
\multicolumn{2}{r}{$\begin{array}{c}\text { Nnmber of } \\
\text { cases }\end{array}$} & $\begin{array}{c}\text { Age } \\
\text { (years) }\end{array}$ & $\begin{array}{c}\text { Relative } \\
\text { weight } \\
(\%)\end{array}$ & Fasting & $30 \mathrm{~min}$ & $60 \mathrm{~min}$ & $120 \mathrm{~min}$ \\
$\begin{array}{c}\text { Healthy } \\
\text { control }\end{array}$ & 17 & $30.4 \pm 6.8$ & $97.5 \pm 8.4$ & $86.6 \pm 5.8$ & $125.3 \pm 14.1$ & $110.6 \pm 20.0$ & $80.9 \pm 11.2$ \\
MND & 31 & $49.8 \pm 12.9$ & $94.4 \pm 9.5$ & $94.8 \pm 15.0^{*}$ & $146.5 \pm 33.4^{*}$ & $144.7 \pm 41.0 \dagger$ & $127.9 \pm 48.3 \ddagger$ \\
ALS & 23 & $49.9 \pm 14.2$ & $94.1 \pm 10.6$ & $94.0 \pm 15.8$ & $141.3 \pm 33.0$ & $140.6 \pm 39.5 \dagger$ & $128.2 \pm 47.6 \ddagger$ \\
SCD & 20 & $58.5 \pm 13.1$ & $100.2 \pm 18.3$ & $91.2 \pm 12.6$ & $149.7 \pm 25.9 \dagger$ & $146.3 \pm 40.0 \dagger$ & $107.4 \pm 28.00_{\ddagger}^{\ddagger}$ \\
OPCA & 13 & $59.3 \pm 11.4$ & $103.5 \pm 19.3$ & $94.8 \pm 13.7^{*}$ & $150.8 \pm 33.0 \dagger$ & $143.4 \pm 41.1 \dagger$ & $111.8 \pm 29.3 \ddagger$ \\
\hline
\end{tabular}

Values are expressed as mean \pm S.D.

Significant differences (Student's $t$-test) are indicated as: ${ }^{*} p<0.05 ; \dagger p<0.01 ; \ddagger p<0.005$.

TABLE 5. Classification of MND and SCD patients on the basis of the results of oral GTT

$\begin{array}{lrrr} & \text { Male } & \text { Female } & \text { Total }(\%) \\ \text { MND } & & & \\ \quad \text { Normal } & 12 & 3 & 15(48) \\ \quad \text { Impaired glucose tolerance } & 10 & 2 & 12(39) \\ \quad \text { Diabetes mellitus } & 3 & 1 & 4(13) \\ \text { SCD } & & & \\ \quad \text { Normal } & 10 & 2 & 12(60) \\ \text { Impaired glucose tolerance } & 3 & 4 & 7(35) \\ \text { Diabetes mellitus } & 0 & 1 & 1(5)\end{array}$

IRI level during $50 \mathrm{~g}$ oral GTT. IRI levels were comparable at 30 and $60 \mathrm{~min}$ but rather higher at 0 and $120 \mathrm{~min}$ in both MND and SCD, when compared with the healthy control group. These differences reached statistical significance in OPCA (Table 6). It was concluded that pancreatic insulin secretion was not impaired but rather excessively responded to hyperglycemia. There was 
TABLE 6. IRI levels during $50 \mathrm{~g}$ oral GTT

$\begin{array}{cccccc} & \begin{array}{c}\text { Number of } \\ \text { cases }\end{array} & \text { Fasting } & 30 \mathrm{~min} & 60 \mathrm{~min} & 120 \mathrm{~min} \\ \begin{array}{c}\text { Healthy } \\ \text { control }\end{array} & 17 & 5.7 \pm 2.0 & 70.4 \pm 42.7 & 63.5 \pm 36.9 & 18.4 \pm 11.1 \\ \text { MND } & 31 & 7.6 \pm 5.9 & 67.0 \pm 42.1 & 57.2 \pm 41.0 & 44.0 \pm 60.7 \\ \text { ALS } & 23 & 7.9 \pm 6.7 & 67.5 \pm 35.4 & 60.3 \pm 44.3 & 46.6 \pm 67.5 \\ \text { SCD } & 20 & 8.5 \pm 4.1^{*} & 81.5 \pm 58.0 & 76.1 \pm 66.8 & 36.8 \pm 29.5^{*} \\ \text { OPCA } & 13 & 8.1 \pm 4.2^{*} & 72.2 \pm 40.8 & 57.3 \pm 31.2 & 31.2 \pm 21.6^{*}\end{array}$

Values are expressed as mean \pm S.D.

Significant differences (Student's $t$-test) are indicated as: $* p<0.05$.

TABLE 7. Glycosylated hemoglobin level in patients with MND and SCD

$\begin{array}{lccc}\text { Healthy control } & \begin{array}{c}\text { Number of } \\ \text { cases }\end{array} & \begin{array}{c}\text { Age } \\ \text { (years) }\end{array} & \begin{array}{c}\text { Glycosylated } \\ \text { hemoglobin (\%) }\end{array} \\ \text { MND } & 17 & 30.4 \pm 6.8 & 6.59 \pm 0.23 \\ \quad \text { ALS total } & 37 & 48.0 \pm 11.3 & 6.55 \pm 0.71 \\ \quad \text { normal GTT } & 21 & & 6.56 \pm 0.84 \\ \text { SCD } & 11 & & 6.24 \pm 0.55^{*} \\ & 28 & 54.8 \pm 13.3 & 6.94 \pm 1.18\end{array}$

Values are expressed as mean \pm s.D.

Significant difference (Student's $t$-test) is indicated as: $* p<0.05$. "total" denotes the group including all ALS patients for whom GTT was performed. "normal GTT" denotes the group consisting of ALS patients in whom GTT was proved to be normal.

no correlation between the plasma triglyceride level and IRI level at $120 \mathrm{~min}$.

Glycosylated hemoglobin. The mean values of glycosylated hemoglobin levels were $6.59,6.55$ and $6.94 \%$ in the healthy control, MND and SCD groups, respectively. In patients with MND, glucose tolerance was unequivocally decreased and the fasting glucose level was significantly higher than that in the healthy control group. Hence, it was expected that the glycosylated hemoglobin level was not lower but rather higher in the MND group than in the healthy control group. When the ALS patients in whom GTT was proved to be normal were picked up, their mean value was $6.24 \%$ which was significantly lower than that of the healthy control group. The mechanism for this paradoxical phenomenon remains to be resolved.

\section{Discussion}

In the present study metabolic derangements common to two degenerative diseases of the nervous system, MND and SCD, were disclosed; lowered HDL cholesterol level, increased plasma triglyceride level, impaired glucose metabolism and normal or higher insulin response to glucose loading. 
Recently attention has been focused on the anti-atherogenic action of HDL to reduce the incidence of cardiovascular events. However, the HDL cholesterol level may be reduced in certain diseases other than atherosclerotic vascular diseases; e. g., hepatic disease (Vergani and Dioguardi 1978), hyper- and hypothyroidism (Agdeppa et al. 1979), hypopituitarism (Sagel et al. 1979), quadriplegia (Heidenberg et al. 1981) and anemia (unpublished data). Although the HDL cholesterol level may be reduced by augmented catabolism, it is largely dependent on the rate of hydrolysis of triglyceride-rich lipoprotein which is regulated by lipoprotein lipase (LPL) activity (Nikkilä et al. 1978). In the present study, the HDL cholesterol level was significantly reduced in patients with either MND or SCD, suggesting that the lowered activity of LPL may be responsible for this reduction. This possibility is supported by the concomitant increase of the plasma triglyceride level.

LPL is believed to be synthesized in the parenchymal cells from which it is secreted and transported to the luminal surface of the capillary endothelial cells on which lipoprotein triglyceride is hydrolyzed (Nilsson-Ehle et al. 1976). It is accepted that approximately $80 \%$ of chylomicron and VLDL triglyceride fatty acids are metabolized in adipose tissue and muscle (Augustin and Greten 1979). Nikkilä et al. (1980) who determined the LPL activity in biopsies taken from adipose tissue and skeletal muscle of active runners, revealed that long-distance runners undergoing continuous endurance training showed remarkably high LPL activities not only in their thigh muscle but also in subcutaneous adipose tissue as compared to short-distance runners and sedentary controls. These findings strongly suggest that physical activity may increase LPL activity of skeletal muscle and adipose tissue, leading to a remarkable elevation of HDL cholesterol level.

It was clearly shown that glucose metabolism was impaired in patients with not only MND but also SCD, that is, intolerance to oral glucose loading is not specific to MND, as Collis and Engel (1968) previously pointed out. This was also the case with patients with either ALS or OPCA. The incidences of diabetes mellitus were not high in either MND or SCD so that most patients having glucose intolerance were classified into the "impaired glucose tolerance" group. In the present study, insulin response to glucose loading was never observed to be lower in either MND or SCD. These findings are contradictory to the report that the impaired pancreatic secretion of insulin resulted in abnormal glucose metabolism (Gotoh et al. 1972; Nagano et al. 1979), but in agreement with other reports (Mueller and Quick 1970; Gustafson and Störtebecker 1972). Other possible mechanisms by which abnormal glucose tolerance is accounted for are prominent decreases in functioning muscle mass and in physical activity. The possibility of the former mechanism has not been validated in Koerner's study (1976). However, a decrease in functioning muscle mass accompanying physical inactivity seems most likely the major common mechanism for abnormal glucose metabolism (Collis and Engel 1968; Gustafson and Störtebecker 1972).

Skeletal mucle fibers of human adults are classified into rapidly contracting 
fibers (type 2A and 2B) and one slowly contracting fiber (type 1) (Dubowitz and Brooke 1973). Type 1 fibers are resistant to fatigue with a high level of oxidative enzyme activity and a low level of phosphorylase activity. In starved animals, fatty acids represent the major source of substrate for oxidation by the type 1 fiber in which LPL activity is increased. The type 2 fibers are all fast twitch and have a high level of phosphorylase activity.

Buller et al. (1960) demonstrated the mutability of skeletal muscle properties as cross-innervation of fast and slow skeletal muscles by the corresponding motor nerves resulting in slowing down the contraction speed of previously fast muscles and increasing the contraction speed of previously slow muscles. These results were subsequently extended by Bárány and Close (1971) who showed that the changes in contraction speed following cross-innervation were associated with parallel changes in the actin-activated ATPase activity of myosin, indicating that a given nerve determines a given fiber type. Accordingly, it is evident that functional properties of skeletal muscle fibers, either differentiating or differentiated, are considerably dependent on the dominant influence of the innervation. For instance, there are possibilities that synthesis and secretion of LPL, regulation of "glucose receptor space" (Collis and Engel 1968) or metabolic pathways in muscle fibers may be under the dominant influence of nervous input. The intact nerve supply seems essential for the skeletal muscle fibers to fully differentiate into either type fiber, to maintain each distinct metabolic pathway, or to adapt adequately the environmental conditions to change their structure and functional properties.

In patients with MND, skeletal muscle fibers are progressively denervated, resulting in striking changes in metabolic capabilities. In biopsied muscle specimens obtained from patients with SCD, small dark angular fibers, type 1 fiber hypertrophy with type 1 fiber predominance and type grouping were shown, indicating the presence of subclinical denervation (Dubowtiz and Brooke 1973). Similar findings were also obtained in patients with myotonic dystrophy and muscular dystrophy (Brooke and Kaiser 1974). Based on these findings described above, a possibility was presented that clinical or subclinical denervation of skeletal mucle fiber may play an important part in the pathogenesis of abnormalities of lipoprotein and carbohydrate metabolisms observed in either MND or SCD patients. It is likely that physical activity may act on the muscle fibers not only directly by itself but also exert beneficial effects on lipoprotein and carbohydrate metabolisms through the trophic function of nerve supply. Duckworth et al. (1980) who observed the glucose intolerance due to insulin resistance in patients with spinal cord injuries suggested the importance of denervation in glucose intolerance. From this viewpoint it appears that the metabolic abnormalities observed may not have any pathogenetic significance for MND or SCD but are rather considered resultant metabolic derangements. 


\section{Acknowledgments}

We thank Dr. H. Nishitani and Dr. T. Konishi of Utano Hospital for their generous permission to examine 3 patients with MND and 2 patients with SCD under medical control.

\section{References}

1) Agdeppa, D., Macaron, C., Mallik, T. \& Schnuda, N.D. (1979) Plasma high density lipoprotein cholesterol in thyroid disease. J. clin. Endocr. Metab., 49, 726-729.

2) Augustin, J. \& Greten, H. (1979) The role of lipoprotein lipase - molecular properties and clinical relevance. In: Atherosclerosis, vol. 5, edited by R. Paoletti \& A.M. Gotto, Raven Press, New York, pp. 91-124.

3) Bárány, M. \& Close, R.I. (1971) The transformation of myosin in cross-innervated rat muscles. J. Physiol., 213, 455-474.

4) Barlow, M.H., McFarlin, D.E. \& Schalch, D.S. (1965) An unusual type of diabetes mellitus with marked hyperinsulinism in patients with ataxia telangiectasia. Clin. Res., 23, 530.

5) Boyd, A.E., III., Lebovitz, H.E. \& Feldman, J.M. (1971) Endocrine function and glucose metabolism in patients with Parkinson's disease and their alteration by Ldopa. J. clin. Endocr. Metab., 33, 829-837.

6) Brooke, M.H. \& Kaiser, K.K. (1974) The use and abuse of muscle histochemistry. Ann. N.Y. Acad. Sci., 228, 121-144.

7) Buller, A.J., Eccles, J.C. \& Eccles, R.M. (1960) Interactions between motoneurones and muscles in respect of the characteristic speeds of their responses. J. Physiol., 150, 417-439.

8) Caughey, J.E. \& Saucier, G. (1962) Endocrine aspects of dystrophia myotonica. Brain, 85, 711-731.

9) Collis, W.J. \& Engel, W.K. (1968) Glucose metabolism in five neuromuscular disorders. Neurology (Minneap.), 18, 915-925.

10) Danowski, T.S., Bastiani, R.M., McWilliams, F.D., Mateer, F.M. \& Greenman, L. (1956) Muscular dystrophy. IV. Endocrine studies. Amer. J. Dis. Child., 91, 356-364.

11) Dreyfus, J.C., Schapira, G. \& Schapira, F. (1954) Biochemical study of muscle in progressive muscular dystrophy. J. clin. Invest., 33, 794-797.

12) Dubowitz, V. \& Brooke, M.H. (1973) Muscle Biopsy: A Modern Approach, W.B. Saunders, New York, pp. 34-73.

13) Duckworth, W.C., Solomon, S.S., Jallepalli, P., Heckemeyer, C., Finnern, J. \& Powers, A. (1980) Glucose intolerance due to insulin resistance in patients with spinal cord injuries. Diabetes, 29, 906-910.

14) Gertler, M.M., Rosenberger, J.L. \& Leetma, H.E. (1972) Identification of individuals with covert ischemic thrombotic cərebrovascular disease: a discriminant function analysis. Stroke, 3, 764-771.

15) Gotoh, F., Kitamura, A., Koto, A., Kataoka, K. \& Atsuji, H. (1972) Abnormal insulin secretion in amyotrophic lateral sclerosis. J. neurol. Sci., 16, 201-207.

16) Gustafson, A. \& Störtebecker, P. (1972) Vascular and metabolic studies of amyotrophic lateral sclerosis. II. Lipid and carbohydrate metabolism. Neurology (Minneap.), 22, 528-536.

17) Heidenberg, D., Rubinstein, A., Levtov, O., Werbin, B. \& Tamir, I. (1981) Serum lipids and lipoprotein concentrations in young quadriplegic patients. Atherosclerosis, 39, 163-167.

18) Hewér, R.L. \& Robinson, N. (1968) Diabetes mellitus in Friedreich's ataxia. $J$. Neurol. Neurosurg. Psychiat., 31, 226-231.

19) Huang, Y.S., Nestruck, A.C., Barbeau, A., Bouchard, J.P. \& Davignon, J. (1978) Plasma lipids and lipoproteins in Friedreich's ataxia and familial spastic ataxia evidence for an abnormal composition of high density lipoproteins. Canad. J. neurol. Sci., 5, 149-155. 
20) Ionǎşescu, V. \& Luca, N. (1963) Investigation on carbohydrate metabolism in progressive muscular dystrophies. Psychiat. Neurol. (Basel), 146, 309-325.

21) Ionăşescu, V. \& Luca, N. (1964) Studies on carbohydrate metabolism in amyotrophic lateral sclerosis and hereditary proximal spinal muscular atrophy. Acta neurol. scand., 40, 47-57.

22) Ionǎşescu, V., Luca, N., Vuia, O. \& Popa, V. (1968) Respiratory control and oxidative phosphorylation in the denervated muscle of patients with amyotrophic lateral sclerosis. Acta neurol. scand., 44, 440-456.

23) Jacobson, W.E., Schultz, A.L. \& Anderson, J. (1955) Endocrine studies in 8 patients with dystrophia myotonica. J. clin. Endocr. Metab., 15, 801-810.

24) Jakobson, T. (1967) Glucose tolerance and serum lipid levels in patients with cerebrovascular disease. Acta med. scand., 182, 233-243.

25) Koerner, D.R. (1976) Abnormal carbohydrate metabolism in amyotrophic lateral sclerosis and Parkinsonism-dementia on Guam. Diabetes, 25, 1055-1065.

26) Lee, F.I. \& Hughes, D.T.D. (1964) Systemic effects in dystrophia myotonica. Brain, 87, 521-535.

27) Lipman, I.J., Boykin, M.E. \& Flora, R.E. (1974) Glucose intolerance in Parkinson's disease. J. chron. Dis., 27, 573-579.

28) Marshall, J. (1959) Observations on endocrine function in dystrophia myotonica. Brain, 82, 221-231.

29) Metropolitan Life Ins. Co. (1942) Ideal weight for women. Stat. Bull., 23, 6.

30) Metropolitan Life Ins. Co. (1943) Ideal weight for men. Stat. Bull., 24, 6.

31) Mueller, P.S. \& Quick, D.T. (1970) Studies of glucose, insulin and lipid metabolism in amyotrophic lateral sclerosis and other neuromuscular disorders. J. Lab. clin. Med., 76, 190-200.

32) Nadler, C.S., Steiger, W.A., Troncelleti, M. \& Durant, T.M. (1950) Dystrophia myotonica, with special reference to endocrine function (Klinefelter's syndrome). $J$. clin. Endocr., 10, 630-635.

33) Nagano, Y., Tsubaki, T. \& Chase, T.N. (1979) Endocrinologic regulation of carbohydrate metabolism. Amyotrophic lateral sclerosis and Parkinsonism-dementia on Guam. Arch. Neurol., 36, 217-220.

34) National Diabetes Data Group (1979) Classification and diagnosis of diabetes mellitus and other categories of glucose intolerance. Diabetes, 28, 1039-1057.

35) Nikkilä, E.A., Taskinen, M.R. \& Kekki, M. (1978) Relation of plasma high density lipoprotein cholesterol to lipoprotein-lipase activity in adipose tissue and skeletal muscle of man. Atherosclerosis, 29, 497-501.

36) Nikkilä, E.A., Kuusi, T., Harno, K., Tikkanen, M. \& Taskinen, M.R. (1980) Lipoprotein lipase and hepatic endothelial lipase are key enzymes in the metabolism of plasma high density lipoproteins, particularly of $\mathrm{HDL}_{2}$. In: Atherosclerosis $V$, edited by A.M. Gotto, Springer-Verlag, New York, pp. 387-392.

37) Nilsson-Ehle, P., Garfinkel, A.S. \& Schotz, M.C. (1976) Intra- and extra-cellular forms of lipoprotein lipase in adipose tissue. Biochim. biophys. Acta, 431, 147-156.

38) Noma, A., Nezu-Nakayama, K., Kita, M. \& Okabe, H. (1978) Simultaneous determination of serum cholesterol in high- and low density lipoproteins with use of heparin, $\mathrm{Ca}^{2+}$, and an anion-exchange resin. Clin. Chem., 24, 1504-1508.

39) Podolsky, S. (1975) Diabetes mellitus in Friedreich's ataxia and Huntington's chorea. Mod. Probl. Paediat., 12, 235-24l.

40) Podolsky, S. \& Sheremata, W.A. (1970) Insulin-dependent diabates mellitus and Friedreich's ataxia in siblings. Metabolism, 19, 555-561.

41) Podolsky, S., Leopold, N.A. \& Sax, D.S. (1972) Increased frequcncy of cliabetes mellitus in patients with Huntington's chorea. Lancet, 1, 1356-1358.

42) Podolsky, S., Pothier, A. \& Krall, L.P. (1964) Association of diabetes m:llitus and Friedreich's ataxia: A study of two siblings. Arch. intern. Med., 114, 533-538.

43) Quick, D.T. \& Greer, M. (1967) Pancreatic dysfunction in patients with amyotrophic lateral sclerosis. Neurology (Minneap.), 17, 112-116. 
44) Sagel, J., Lopes-Virella, M.F., Levine, J.H. \& Colwell, J.A. (1979) Decreased high density lipoprotein cholesterol in hypopituitarism. J. clin. Endocr. Metab., 49, 753756 .

45) Steinke, J. \& Tyler, H.R. (1964) The association of amyotrophic lateral sclerosis (motor neuron disease) and carbohydrate intolerance, a clinical study. Metabolism, 13, 1376-1381.

46) Utterback, R.A., Cummins, A.J., Cape, C.A. \& Goldenberg, J. (1970) Pancreatic function in amytrophic lateral sclerosis. J. Neurol. Neurosurg. Psychiat., 33, 544-547.

47) Van Woert, M.H. \& Mueller, P.S. (1971) Glucose, insulin and free fatty acid metabolism in Parkinson's disease treated with levodopa. Clin. Pharm. Therap., 12, 360-367.

48) Vergani, C. \& Dioguardi, N. (1978) Serum total lipids, lipoprotein cholesterol and apolipoprotein-A in acute viral hepatitis and chronic liver disease. In: International Conference on Atherosclerosis, edited by L.A. Carlson, Raven Press, New York, pp. 283-289.

49) Walker, J.L., Chamberlain, S. \& Robinson, N. (1980) Lipids and lipoproteins in Friedreich's ataxia. J. Neurol. Neurosurg. Psychiat., 43, 111-117. 